\title{
Penggunaan Project-Based Learning dalam Meningkatkan Speaking Skill
}

\author{
Sahrawi \\ IKIP-PGRI Pontianak, Indonesia \\ E-mail: awihasanah@gmail.com
}

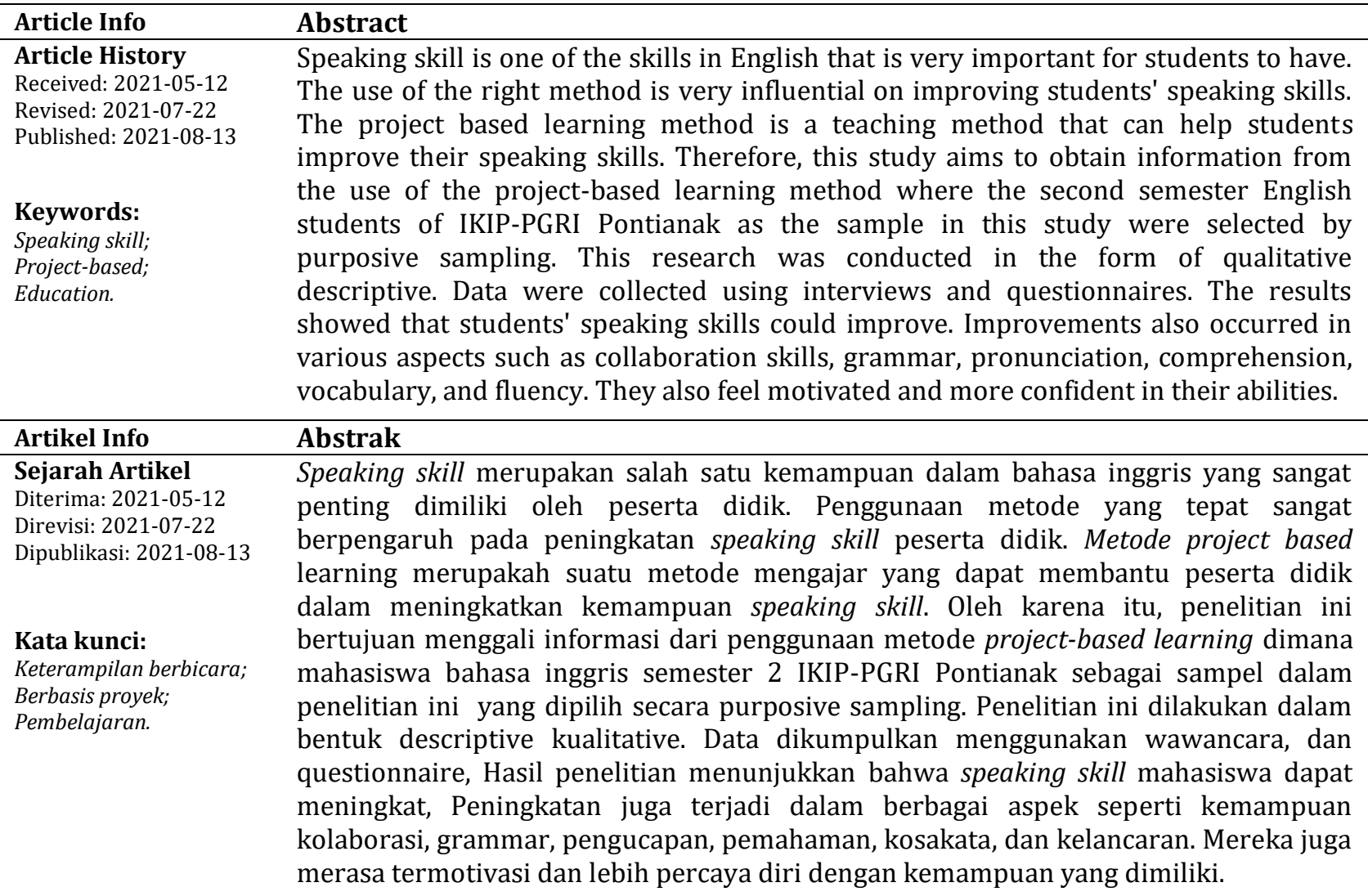

\section{PENDAHULUAN}

Bahasa Inggris sebagai bahasa internasional memiliki peran yang sangat penting dalam kehidupan sehari-hari. Speaking skill merupakan salah satu dari empat skill dalam bahasa inggris yang harus dikuasai oleh mahasiswa. Speaking skill harus sering dilatih atau dipraktikkan agar bisa meningkat. Dengan kemampuan speaking skill yang baik akan mempermudah mahasiswa dalam melakukan komunikasi menggunakan bahasa inggris. Linse (2005) mengatakan bahwa kemampuan bahasa inggris khususunya speaking skill sangat penting agar dapat berkomunikasi dengan orang lain secara global, di Indonesia, bahasa inggris masih sangat jarang digunakan dalam kehidupan sehari-hari. Dengan kata lain, speaking skill hanya digunakan didalam kelas sehingga menyebabkan banyak mahasiswa merasa sulit berkembang karena tidak ada wadah atau lawan bicara untuk mempraktekkan ilmu yang sudah diperoleh dari dalam kelas ke kehidupan sehari-hari mereka. Disamping itu, penggunaan metode mengajar yang kurang tepat juga akan menurunkan motivasi dan minat belajar peserta didik dalam mengikuti pembelajaran.

Proses belajar mengajar yang efektif akan memberikan hasil yang baik pada peserta didik. Dengan kata lain, penggunaan metode mengajar yang tepat akan membantu peserta didik meningkatkan kemampuan speaking skill. Project based Learning (PBL) merupakan salah satu metode yang dapat membantu peserta didik meningkatkan kemampuan speaking skill mereka dalam konteks natural dimana peserta didik belajar melalui tugas yang ditentukan sendiri dengan bantuan pengajar sehingga peserta didik menjadi aktif dalam pembelajaran. Menurut Patton (2012) dalam metode PBL, peserta didik melakukan design sendiri pekerjaan dan rencana 
yang akan dilakukan, PBL merupakan metode yang dapat mempermudah pengajar mencapai tujuan pembelajaran. Fragoulis (2009) dalam bukunya mengatakan bahwa ada banyak kelebihan dari penggunaan PBL dalam pengajaran bahasa inggris sebagai bahasa asing yaitu PBL memberikan kontekstual dan pembelajaran yang berharga bagi peserta didik, menciptakan lingkungan yang optimal dalam praktek speaking bahasa inggris, peserta didik dapat berpartisipasi secara aktif dalam pembelajaran, meningkatkan minat, motivasi, keterkaitan, kegembiraan peserta didik, dan meningkatkan kemampuan kolaborative.

Metode PBL juga memberikan kesempatan bagi peserta didik mengembangkan kemampuan dalam kondisi nyata. Fauziati (2014) mengatakan bahwa penggunaan metode PBL memberikan peserta didik kesempatan mengerjakan tugas yang diberikan sehingga mereka tidak hanya belajar tetapi juga mempraktekkan bahasa inggris serta mengemba-ngkan berbagai macam kemampuan penting lainnya seperti teamwork, critical thinking, dan presentasi. Begitu juga sebaliknya, kemampuan speaking skill peserta didik tidak akan berkembang jika mereka masih merasa khawatir, tidak percaya diri, dan tidak memiliki teman atau lawan bicara untuk mempraktikkan kemampuan yang sudah dipelajari di dalam kelas, dengan menggunakan project based learning, peserta didik dapat di stimulasi dalam mengembangkan dan meningkatkan kemampuan bahasa inggris mereka sehingga mereka dapat menggunakan bahasa secara lancar, tepat, dan percaya diri. Mereka juga dapat meningkatkan kemampuan dalam membuat keputusan serta melakukan kolaborasi dengan teman yang lainnnya.

\section{METODE PENELITIAN}

Jenis Penelitian yang digunakan dalam penelitian ini adalah deskriptive kualitatif, dengan Sample penelitian ini dipilih secara purposive sampling yaitu mahasiswa bahasa inggris IKIP PGRI Pontianak semester 2, Jumlah peserta sebanyak 37 orang. Instrumen yang digunakan berupa questionnaire dan wawancara, adapun, Teknik analisis data yang digunakan dalam penelitian ini adalah teknik analisis data kualitatif deskriptif. Miles dan Huberman (Sugiyono, 2017: 337) mengemukakan bahwa aktivitas dalam analisis data kualitatif dilakukan secara interaktif dan berlangsung secara terus menerus sampai tuntas, sehingga datanya sudah jenuh, peneliti menggunakan analisis data model
Miles dan Huberman yang meliputi tiga tahapan, yakni reduksi data, display data, dan penarikan kesimpulan, berikut ini adalah gambar skema analisis data model analisis data menurut Miles dan Huberman:

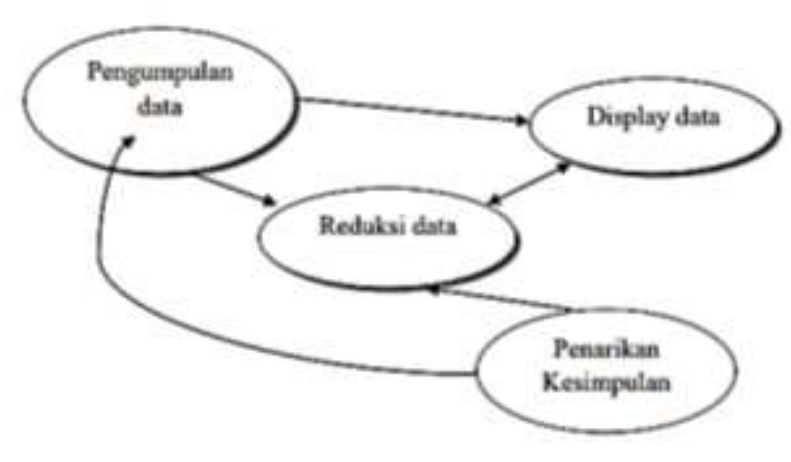

Gambar 1. Skema Model Analisis data Miles dan Huberman (Sugiyono, 2017: 337)

\section{HASIL DAN PEMBAHASAN}

Speaking skill adalah kemampuan mengekpresikan ide, pikiran, atau informasi dalam bentuk verbal. Oleh karena itu, setiap peserta didik harus bisa meningkatkan kemampuan speaking skill agar dapar berkomunikasi secara lancar di dunia internasional. Namun demikian, kemampuan bahasa inggris peserta didik khususnya speaking skill ini sangat dipengaruhi oleh metode mengajar yang tepat. Dalam penerapan metode ini, pendidik melakukan beberapa langkah seperti memulai tugas, dimana pengajar menyapa peserta didik, memeriksa kehadiran dan menyampaikan tujuan dari pembelajaran. Peserta didik melakukan brainstorming dan mengaktifkan pengetahuan awal mereka. Pengajar juga dapat menunjukkan gambar atau video yang berkaitan dengan tugas yang akan dikerjakan oleh peserta didik. Peserta didik juga dapat melakukan komunikasi atau diskusi dengan teman satu group.

Langkah yang selanjutnya peserta didik mengembangkan tugas, mereka mengerjakan tugas yang diberikan diluar sekolah dengan teman satu group, peserta didik tetap dapat bertanya kepada pengajar atau teman yang lain jika mengalami kendala. Kemudian peserta didik menyampaikan atau mempresentasikan hasil kerjaan yang telah dilakukan dengan teman kelompok dimana peserta didik dapat membawa alat bantu atau media seperti power point atau gambar sehingga mereka memiliki kesempatan untuk mengeksplor kemampuan speaking mereka baik secara berkelompok atau sendiri- 
sendiri, sementara pengajar dapat melakukan penilaian selama mahasiswa melakukan presentasi. Langkah yang selanjutnya yaitu penilaian yang dapat dilakukan oleh pengajar dan teman kelas, pengajar atau teman memberikan komentar atau saran terhadap penampilan yang telah dilaksnakan, kemudian pengajar juga dapat melakukan refleksi terhadap pembelajaran yang telah dilakukan.

Hasil penelitian yang diperoleh dari wawancara menunjukkan bahwa penggunaan metode mengajar project based learning memberikan kontribusi yang signifikan dalam meningkatkan speaking skill mahasiswa, peserta didik mengikuti pembelajaran secara aktif. Mereka senang melakukan tugas yang diberikan. Perubahan yang sangat signifikan juga terjadi pada motivasi serta minat peserta didik, meskipun masih ada beberapa dari mereka yang masih pasif, adapun tujuan utama dari penelitian ini dapat menyimpulkan bahwa speaking skill secara umum dari peserta didik juga mengalami perubahan yang baik. Hasil penelitian ini juga didukung oleh questionnaire yang dibagikan kepada peserta didik menggunakan google form. Hasil analisis meunjukkan bahwa 82\% dari partisipan sangat setuju akan penggunaan metode project based learning.

Penggunaan metode mengajar yang tepat akan membantu pengajar dalam mencapai tujuan pembelajaran dan juga dapat membantu peserta didik meningkatkan kemampuan mereka. Penggunaan metode PBL mendapatkan respon yang positif dari peserta didik. Hal ini dapat dilihat pada table berikut ini.

Tabel 1. Responses Mahasiswa tentang ProjectBased Learning

\begin{tabular}{|c|c|c|c|c|c|}
\hline $\begin{array}{l}\text { Questionnaire } \\
\text { Items }\end{array}$ & $\begin{array}{l}\text { Strongly } \\
\text { agree }\end{array}$ & Agree & $\begin{array}{c}\text { No } \\
\text { opinion }\end{array}$ & $\begin{array}{c}\text { Stron } \\
\text { gly } \\
\text { disag } \\
\text { ree }\end{array}$ & $\begin{array}{l}\text { Disa } \\
\text { gree }\end{array}$ \\
\hline $\begin{array}{l}\text { 1. Saya dapat } \\
\text { bekerjasama } \\
\text { dengan } \\
\text { teman yang } \\
\text { lain dalam } \\
\text { kelas }\end{array}$ & (82\%) & $(6 \%)$ & $(6 \%)$ & $(4 \%)$ & $(2 \%)$ \\
\hline $\begin{array}{l}\text { 2. Saya suka } \\
\text { dengan } \\
\text { metode } \\
\text { mengajar PBL } \\
\text { dalam kelas } \\
\text { speaking }\end{array}$ & (90\%) & $(8 \%)$ & $(0 \%)$ & $(2 \%)$ & $(0 \%)$ \\
\hline $\begin{array}{l}\text { 3. Saya sangat } \\
\text { antusias } \\
\text { melakukan } \\
\text { diskusi di } \\
\text { dalam kelas }\end{array}$ & $(74 \%)$ & $(12 \%)$ & $(6 \%)$ & $(4 \%)$ & $(4 \%)$ \\
\hline
\end{tabular}

4. Metode PBL

dapat

meningkatka

n

kemampuan

$(90 \%) \quad(6 \%) \quad(0 \%)$

$(2 \%)$

$(2 \%)$

kolaborasi

dan percaya

diri saya

5. Metode PBL

memberikan

kesempatan

praktek

$(80 \%) \quad(10 \%) \quad(4 \%) \quad(4 \%)$

$(2 \%)$

speaking

skill.

6. PBL

meningkatka

n motivasi

$(78 \%) \quad(8 \%) \quad(6 \%)$

$(4 \%) \quad(4 \%)$

belajar saya

7. Metode PBL

menghubung

kan dengan

pengetahuan

$(84 \%) \quad(8 \%) \quad(6 \%)$

$(2 \%) \quad(0 \%)$

awal saya

8. Saya lebih

mudah

mengerti

dengan

$(84 \%) \quad(12 \%) \quad(4 \%) \quad(0 \%)$

$(0 \%)$

melakukan

kerjasama

9. Kemampuan

saya lebih

meningkat

setelah

menggunaka

$n$ metode PBL

$(78 \%)$

seperti

grammar,

fluency,

vocabulary

10. PBL sangat

cocok dengan

cara saya

$(80 \%) \quad(6 \%) \quad(6 \%)$

$(4 \%) \quad(4 \%)$

belajar

Hasil penelitian tersebut didukung oleh Febriawati (2012), dimana dalam penelitiannya menyatakan bahwa terdapat perubahan yang signifikan dalam speaking skill peserta didik ketika mengajar menggunakan metode project based learning, perubahan tersebut juga terjadi pada aspek spesifik yaitu kosakata, ketepatan, dan kelancaran dalam berbiciara, penggunaan metode PBL juga membuat peserta didik menjadi ebih percaya diri dalam melakukan komunikasi dan mereka juga termotivasi dalam mengikuti proses belajar mengajar, hasil penelitian tersebut juga didukung oleh Tamin \& Grant (2013) bahwa PBL Mendukung, menfasilitasi, dan meningkatkan proses pembelajaran. 


\section{SIMPULAN}

Speaking skill merupakan salah satu kemampuan yang harus dimiliki oleh peserta didik agar dapat berkomunikasi dengan lancar menggunakan bahasa inggris, Speaking skill merupakan suatu proses interaksi yang terjadi antara satu orang atau lebih secara lisan untuk mengungkapkan ide, informasi, atau perasaaan kepada orang lain, Speaking skill akan meningkat jika dudukung oleh pengajar dengan menggunakan metode yang tepat, metode yang dapat menfasilitasi dan memotivasi peserta didik, metode yang dapat meningkatkan minat belajar dan kemampuan peserta didik, Penggunaan metode yang tepat akan membantu mencapai tujuan akhir dari pembelajaran secara maksimal. PBL merupakan salah satu metode mengajar dimana peserta didik memperoleh pengetahuan dan kemampuan dengan mengerjakan tugas yang diberikan oleh pengajar selama proses pembelajaran. Proses penerapan metode PBL focus pada konsep dimana peserta didik difasilitasi untuk melakukan investigasi terhadap tugas yang diberikan sehinnga mereka menjadi lebih aktif dalam mengikuti pembelajaran dan melakukan diskusi dengan teman yang lain, PBL merupakan metode yang tepat dalam meningkatkan kemampuan peserta didik.

Kesimpulan dari hasil penelitian menunjukkan bahwa pelaksanaan metode project based learning dapat meningkatkan speaking skill peserta didik, Mereka dapat berpartisipasi secara langsung dengan melakukan presentasi tugas yang telah diberikan dimana pengajar dan teman yang lainnya dapat memberikan feedback dan saran secara langsung baik dalam group maupun secara personal. Penerapan metode PBL memberikan dampak yang positif bagi peserta didik karena mereka menjadi termotivasi dan senang mengikuti pembelajaran sehingga mereka menjadi lebih udah faham terhadap materi di dalam kelas, Secara umum penggunaan metode PBL dapat meningkatkan kemampuan mahasiswa semester 2 program studi pendidikan bahasa inggris IKIPPGRI Pontianak khususnya dalam speaking skill. Disamping itu, penggunaan metode PBL juga dapat meningkatkan kemampuan dalam bagian spesifik seperti grammar, pengucapan, pemahaman, kosakata, dan fluency.

Peserta didik juga memperoleh pengalaman baru dengan melakukan tugas bersama-sama dengan teman mereka dalam menyampaikan ide mereka, melakukan negosiasi, serta menghargai perbedaan pendapat diantara mereka. Mereka juga dapat melaksanakan atau mempraktikkan speaking skill mereka secara langsung dalam kehidupan sehari-hari sehingga pengajar juga dapat melakukan interaksi secara lebih intens terhadap mahasiswa.

\section{DAFTAR RUJUKAN}

Fauziati, Endang. (2014). Methods of Teaching English as A Foreign Language: Traditional Method, Designer Method, Communicative Method, and Scientific Approach.

Febriawati, D. A. (2012) Improving students' speaking skills through Project-Based Learning at grade eight of SMP N 1 Kalasan. Unpublished Bachelor's thesis. Universitas Negeri Yogyakarta, Yogyakarta

Fragoulis, L. (2009). Project-Based Learning in Teaching of English as A Foreign Language in Greek Primary Schools: From Theory to practice. (A Journal). English Language Teaching. Vol. 2 September 2009.

Fragoulis, L. (2009). Project-Based Learning in Teaching of English as A Foreign Language in Greek Primary Schools: From Theory to Practice. (A Journal). English Language Teaching. Vol. 2 September 2009.

Indah Afrianti. (2021). The Effectiveness of Study Tour Towards Students' Speaking Skill. Ainara Journal (Jurnal Penelitian Dan PKM Bidang Ilmu Pendidikan),2(2), 133$142 . \quad$ Retrieved from http://journal.ainarapress.org/index.php/ai $\mathrm{nj} /$ article/view/43

Linse, C.T. (2005). Practical English Language Teaching: Young Learners. New York: McGraw-Hill ESL/ELT.

Nur Wahyuni, \& Mulya Yusnarti. (2020). The Effectiveness of Discussion Techniques on First Grade Students' Speaking Skills Junior High School. Ainara Journal Jurnal Penelitian Dan PKM Bidang Ilmu Pendidikan), 1(1), 17-23. https://doi.org/10.1234567/ainarajournal.v $1 \mathrm{i} 1.9$

Patton, A. (2012). Work That Matters: The Teacher's Guide to Project-Based Learning. The Paul Hamlyn Foundation. 
Sugiyono. 2017. Metode Penelitian Pendidikan. Bandung: Alfabeta.

Tamin, S. R. , \& Grant, M. M. (2013). Definitions and uses: Case study of teachers implementing project-based learning. Interdisciplinary Journal of Problem-Based Learning, 7(2), 71-101. 